\title{
Questionable Aspects of Oliver Sacks' (1985) Report
}

Makoto Yamaguchi

Published online: 18 July 2007

(C) Springer Science+Business Media, LLC 2007

\section{Erratum to: J Autism Dev Disord} DOI 10.1007/s10803-006-0257-0

In the third paragraph of the pdf version of this letter, "Yamaguchi, in press" should be "Yamaguchi, 2005".
In the denominator of the formula that is displayed following the fourth paragraph in the html version of the letter, " $\log N$ " should be "log $n$ ".

The online version of the original article can be found under doi: 10.1007/s10803-006-0257-0.

M. Yamaguchi $(\bowtie)$

The University of Tokyo, Hongo, Japan

e-mail: myamag@mail.ecc.u-tokyo.ac.jp 